\title{
MÚSICA, PESQUISA e INFÂNCIA: CANTORIAS DO REPENTE
}

\author{
Dulcimarta Lemos Lino ${ }^{1}$
}

\section{Resumo}

O presente artigo reflete sobre a pesquisa de música com crianças, destacando a processualidade inventiva do pesquisador como uma necessidade emergente. Apresenta dois pontos de escuta considerados no trabalho investigativo da autora, quando intencionalmente pretendeu constituir modos improvisados de fazer pesquisa, escutando a música das crianças na escola. Dentro do campo da Sociologia da Infância, destaca o barulhar como a música das crianças e a paisagem sonora enquanto cenário institucionalizado da ação infantil, revelando dois pontos de escuta para movimentar a reflexão acerca do processo investigativo de música com crianças e na infância.

Palavras-chave: Pesquisa de música com crianças; culturas infantis e música; paisagem sonora escolar.

\section{“eu só sei o que é o verso quando ouço minha voz cantando”}

O depoimento acima é dos cantadores do Repente nordestino, testemunho de sua forma de fazer música. Serve como abertura do presente artigo porque sublinha as cantorias intensamente vividas quando se pretende apresentar algumas das inquietações envolvidas no árduo trabalho que envolve a pesquisa com música na infância. Em seu sentido estrito, Repente quer dizer improviso, coisa feita na hora. É o verso que o cantador imagina durante o próprio ato de cantá-lo. Por outro lado, o Repente também tem um sentido mais amplo, e aí é sinônimo de Cantoria de Viola. Designa

\footnotetext{
${ }^{1}$ Doutora em Educação (UFRGS), Mestre em Educação (UFRGS), Licenciada em Educação Artística: habilitação em Música (UFRGS). Professora da UNISINOS (Universidade do Vale do Rio dos Sinos). Endereço: Carlos Gardel 139, apt 401. Bairro Bela Vista, Porto Alegre, RS. Fone: (051) 32373512 - 33327224 - 99542255. E-mail: dulcimarta@terra.com.br.
} 
a arte dos cantadores com tudo o que ela envolve: os modelos poéticos apreendidos, o jeito de cantar, os valores estéticos, os rituais. Tudo, no entanto, tendo como base a arte de improvisar versos (NABUCO, 2008, p.14).

Ao entender que nos últimos dez anos o ato de pesquisar tem exigido do investigador a intensa arte de improvisar, porque não pretendemos circunscrever nossos sujeitos num território específico, nem mesmo encaixá-los em teorias ou paradigmas unificadores que nos dizem respeito, “ouvir a sua voz cantando" é a metáfora aqui utilizada para que, como pesquisadores, assumamos cientificamente a "processualidade inventiva" (ABRAMOWICZ, 2010), que significa ir constituindo modos improvisados de fazer pesquisa, deixando-nos surpreender ludicamente com a potência poética da música das crianças e da infância. Nesse sentido, investigar a música produzida pelas crianças requer escutar sensivelmente a complexidade e a pluralidade envolvida na infância como uma construção social (SIROTA, 1998), nas crianças como atores plurais (LAHIRE, 2001) e na música como uma linguagem heterofônica.

Os inúmeros trabalhos realizados no campo da Sociologia da Infância (PINTO, 1997; SARMENTO, 2007; JAMES, JENKS, PROUT, 1998; BARBOSA, 2006) têm contribuído intensamente para enriquecer e ampliar a referida temática, destacando a importância de ouvir a voz do pesquisador e das crianças como atores sociais, dotados de competência e autonomia. No campo da Educação Musical, esses estudos ainda existem em pequeno número (CAMPBELL, 1998; HORTELIO, 1977; LINO, 2008), o que vem obrigando os pesquisadores a criar seus próprios Repentes, aproximando sentidos instituídos para constituir outros pontos de escuta à medida que se dispõem a ouvir e ir construindo sua própria voz.

Assim, o presente artigo apresenta dois focos de reflexão do pesquisador de música na infância, duas cantorias do Repente, dois versos, dois pontos de escuta: o barulhar como a música das crianças e a paisagem sonora como cenário institucionalizado da ação infantil. Não entendo que esses pontos de reflexão apareçam com maior ou menor relevância no contexto investigativo. Compreendo que eles indicam o meu recorte, ou melhor, algumas das inúmeras cantorias que 
experimentei ao investigar a música das crianças na escola, participando intensamente de sua vida que sempre ressoava os múltiplos, heterogêneos e dissonantes contextos de socialização da infância na contemporaneidade.

\section{"pra começo de conversa"}

Uma investigação que contemple Música e Infância como substantivos plurais entende que o pesquisador deve implicar-se no campo. Assim, ele não trabalha sobre as crianças, mas com as crianças, num lugar onde o imprevisto é acolhido porque implica a sua própria vida social, afetiva, política, imaginária e espiritual. Ao propor uma dimensão poética na pesquisa acadêmica, Barbier (2002, p.15) faz o convite para que o pesquisador seja "verdadeiramente, e talvez, tão simplesmente, um ser humano". A escuta sensível é o caminho metodológico que constitui uma prática humana e social percebida como portadora de uma vetorialidade de referências que ninguém, nem o sujeito, poderá esgotar na análise (BARBIER, 1993).

O trabalho de Barbier (1993) relaciona-se diretamente com a pedagogia de Malaguzzi (1990). Para este, a emergência do humano é condição da tensão estética na qual a "imaginação e a razão se tenham confrontado continuamente na busca de equilíbrios e alternâncias" (HOYUELOS, 2006, p.123), as quais, a partir da prática da escuta e do respeito, possam construir espaços inovadores. Então, ao transgredir esteticamente os limites da cultura e as idéias fixas da tradição pedagógica que ouve o que sabe, e não o que escuta, Malaguzzi (1990) aponta os conceitos de escuta e respeito como complementares e irremediavelmente unidos na prática educativa. Para o autor, "não se pode escutar sem respeitar e não é possível respeitar alguém sem escutá-lo" (HOYUELOS, 2006, p.54). Malaguzzi (1990) afirma que a pesquisa em educação deveria constituir uma audição que aprenda a escutar o ruído, as dissonâncias e as situações que não resultem em resolução, apresentando-se como o único caminho para conhecer a complexidade da infância.

Nesse contexto, pesquisar música com crianças envolve um campo

sem a apropriação de um repertório definido, nem de um modelo normativo de realização [...] [Mas como] um devir plural e criativo, sem patrão e sem projeto, sem uma idéia prescritiva de seu itinerário, e sem uma idéia normativa, autoritária e excludente de seu 
resultado. [...] chegar a ser plenamente humano (LAROSSA, 1996).

Ao sublinhar a habilidade "humana" do pesquisador na investigação Larossa nos convida a refletir sobre todo aquilo quenos liga a vida. Nesse sentido, pretende abrir os ouvidos à complexidade da música na infância, contemplando "a agenda afetiva e pessoal que surpreende e inscreve, em cada instância coletiva, a marca de uma experiência vertical irredutível, ainda que acompanhada sempre da sensação de ser compartilhada" (WISNIK, 2004, p.243). Uma escuta sensível que "exprimida reciprocamente, é uma troca de poemas, de ressentimentos profundos", na qual, sem passar pelo intelecto, aprende-se a "deixar-se ser pego" (BARBIER, 2002, p. 54) pelos movimentos de sentidos que as crianças como atores sociais incorporam e que nossa audição de pesquisador se arrisca a organizar.

Logo, ao escolher como campo investigativo a pesquisa de música com crianças na escola, não posso negar que esta instituição "permanece como um palco conflitual de projetos políticos e pedagógicos que podem tanto orientar-se para uma efetiva ampliação dos direitos das crianças quanto sustentar-se em lógicas de ação que perpetuam a inscrição histórica da dominação" (SARMENTO, 2007, p.40); ou mesmo, variar de uma proposta educacional de um espaço de jogo e recreação a uma proposta fechada que associa à escola de Educação Infantil a preparação da escolaridade posterior (KUHLMANN Jr, 1998).

Ao incorporar historicamente processos de disciplinarização da infância (FOUCAULT, 1997) inerentes à ordem social dominante, bem como viver o declínio e a fragilidade dos programas institucionais (DUBET, 2002), as escolas têm servido para separar as crianças do espaço público. Se a modernidade escolar introduziu a escola como a instituição de acesso à cidadania plena, com igualdade de competências e capacidades para competirem na sociedade, esta escola também possibilitou a "privatização da infância" (WYNESS; HARISSON; BUCHANAN, 2004) que, tanto protegida quanto subordinada à autoridade paternalista adulta, acaba por incorporar as múltiplas “agências da ocupação infantil” (SCRATON, 1997). 
As perspectivas qualitativas em Sociologia da Educação têm nos alertado para o fato de que as pesquisas com crianças na escola vêm acompanhando esses diferentes postulados da vida escolar, reconstituindo a trajetória histórica e social das escolas a partir de recortes espaço-temporais demarcados. Dessa forma, após um extenso período do "movimento da escola científica” (VILLA, 1997), no qual tudo deveria ser mapeado para que possíveis variáveis que condicionavam o funcionamento escolar fossem identificadas com forte sustentação do funcionalismo e da ideologia liberal - ou mesmo assentadas nas teorias da reprodução que, perpetuando o modelo da produção capitalista, verificava como a escola socializava os alunos para o lugar social de mando e obediência — temos, na contemporaneidade, uma exposição de trajetórias de pesquisa que, mais que caminhos a percorrer, servem como pontos de encontro para inspirar reflexões acerca da cultura escolar (ZAGO; CARVALHO; VILELA, 2003).

Tais pontos de encontro acabam por contrapor-se ao processo de institucionalização e rotinização da educação da infância tomado na modernidade. Ao investigar a referida temática, Barbosa (2006, p.71) constatou que as rotinas empreendidas na escola estavam em profunda relação com a construção da modernidade, alterando radicalmente a natureza da vida social cotidiana, além de alcançar os aspectos mais pessoais da vida humana. Por essa razão, as escolas e as fábricas caminhavam na marcha do progresso. As teorias de organização que estabeleciam a rotinização do trabalho na indústria — baseadas nos pressupostos de Taylor (1988) — tornaram-se o modelo hegemônico de todas as organizações sociais ocidentais, definindo um modo de pensar e realizar as atividades cotidianas dentro de um sistema mecanizado e hierarquizado em que a relação entre as pessoas e o tempo linear do capital era metronomicamente medido (BARBOSA, 2006).

Para definir a modernidade, Barbosa (2006) vale-se dos pressupostos de Giddens (1995), que a descrevem num sentido geral como abarcadora das instituições e dos modos de comportamento impostos na Europa após o feudalismo, quando a racionalização, o industrialismo, o urbanismo, a disciplina, o higienismo, a secularidade e a idéia de evolução e progresso adquiriram um caráter histórico mundial. Dessa forma, constitui-se naquele processo histórico a 
institucionalização das crianças pequenas, no qual a demarcação da rotina, da divisão do trabalho, do controle, da normatização e da sua psicologização fica evidente com a expansão da escola. Por essa razão, na modernidade, com o objetivo de simplificar um mundo que estava ficando excessivamente complexo, a educação das crianças pequenas foi construída instrumentalmente com vista a um dever ser, enquadrando essa clientela na rotinização de sua educação à medida que, pouco a pouco, tiravam-lhes o fardo da liberdade, da imaginação e da construção própria (BARBOSA, 2006, p.71-77).

Nesse contexto, os estudos de Woodward (1997, p.4) pontuam que, mesmo que a escola venha sendo usada para demarcar e sustentar significados incorporados pela civilidade e normatização inerentes à modernidade, tais propósitos que poderiam nos prescrever "um senso de nossa própria identidade, de quem somos e a quem pretendemos, apresentam-se completamente atados às questões sobre como a cultura é utilizada para demarcar e sustentar a identidade e a diferença dos grupos”.

Por essa razão, Mafra (2003) sustenta que o contexto escolar não é homogêneo, uniforme e compacto, ele é multidimensional, pluralista e diversificado, ainda que possa ser abordado a partir de ethos culturais unificadores. A autora ainda reforça que tais ethos culturais se mantêm e se transformam ao longo do tempo e das épocas e apontam, em sua transversalidade, para uma desejável integração entre as diversas áreas das ciências da educação. Mafra (2003, p.131) define ethos culturais como o conjunto de valores, atitudes e comportamentos que dão identidade particular à escola, que caracterizam a diferença.

$\mathrm{Na}$ contemporaneidade, escutar a escola exige considerar as forças culturais produzidas como "expressão das contradições vividas pelas culturas não-dominantes dentro dos quadros institucionais" (GORDON, 1990, p.34), compreendendo que a escola não é marcada meramente pelos determinantes institucionais invencíveis. A escola "é a arena vital para a produção da prática e do significado" (GREEN, 1997, p.17) e, como o espaço da diversidade comporta variedade, operando dentro de diferentes discursos. 
Portanto, a escuta da música das crianças na escola reverbera o conflito de valores e ações que se constituem significativamente na integração das crianças, dos adultos, da sociedade, num espaço concreto aberto à incerteza, à complexidade, à instabilidade e à singularidade. Dessa forma, o pesquisador não escuta apenas as músicas consonantes, demarcadas na rotina escolar para normatizar, disciplinar, controlar e higienizar as crianças. Para além dessa descrição prescritiva, o pesquisador em música deixa-se ressoar por “todas as músicas da música” (BRITO, 2007) expressas no improviso heterofônico de experimentar as materialidades sonoras, sentindo corporalmente a música antes de pensá-la com sentido. Assim, sem negligenciar a expressão sonora de sentidos musicais constituídos pelas crianças, o pesquisador torna-se capaz de ouvir seu barulhar como o verso que conjuga o Repente das culturas infantis.

\section{"barulhar a música das crianças"}

Ao escutar a música das crianças na escola (LINO, 2008), compreendi que sua expressão sonora espontânea era o barulhar. Tal ação, quase não aparecia nos tempos de trabalho dispostos na rotina escolar, mas emergia nos tempos livres institucionalizados. Defino tempos de trabalho como aqueles espaços determinados, constantes, regulares e medidos do cotidiano escolar, onde a mediação docente e/ou a monitoração das adultas-professoras é uma constante, isto é, a hora da higiene, a hora do soninho, a hora do lanche, a hora da fruta, a hora do trabalhinho. Os tempos livres são aqui definidos como tempos improvisados, indeterminados e não-lineares, onde as crianças não necessitam prescrever resultados ou alcançar objetivos determinados pelas adultasprofessoras. Os tempos livres emergem institucionalmente como tempos de brincar vividos na brincadeira livre na hora de chegada à escola, na hora do recreio ou hora das festas escolares.

Sem negar que as crianças invadem as brechas provisórias encontradas nos tempos de trabalho instituídos na rotina escolar para expor suas singularidades sonoras plurais, concentrei meu tempo de investigadora na escuta sensível da música que ressoava nos tempos livres das crianças. Aos poucos fui entendendo que esses tempos livres foram constituídos pelas crianças como momentos para barulhar. Nessa ação imprevisível e indeterminada que fluía na diversidade dos 
corpos lançados à sensibilidade de soar, constatei que cada criança apreendia as relações do contexto coletivo e do comportamento musical de uma sociedade, expondo singularidades plurais em performance.

Por existir num tempo improvisado de soar, o barulhar das crianças não quer a sala de concertos. Ele aparece num tempo e num espaço dessacralizado e singular e, por isso, ocupa todo e qualquer lugar onde se possa viver a infância. Sendo um conjunto de elementos sonoros justapostos, o barulhar ressoa num tempo não-linear, emergindo da relação intensa das crianças com os sons. Assim, o tempo de barulhar é a dimensão que parece constituir a compreensão da duração como o suporte que a música necessita para se materializar. Por essa razão, esse tempo se distancia do tempo cronológico, medido, determinado e regular. Poderíamos dizer que o tempo acusticamente identificado no barulhar é o tempo da vivência sem hierarquias, o Acronon $^{2}$, temporalizador de um movimento que, "como o mar, está sempre mudando, mas ao mesmo tempo, está sempre igual" (KOELLREUTER, 2000). Então, o tempo de barulhar é sempre a incidência corporal de um movimento do real com o ficcional, em que as crianças testemunham os processos de estranhamento, investigação e experimentação (RICHTER, 2005). Sem carregar um ponto final, o tempo de barulhar existe atraído pela intensidade de seu fluir no espaço sônico.

Nesse contexto, as crianças têm no corpo e no mundo o território do tempo de barulhar, onde testemunham as limitações outorgadas na fisicalidade desse corpo, dos objetos e das paisagens sonoras que escolhem manipular ou que dispõem no contexto escolar. Vale destacar que as crianças não necessitam de instrumentos musicais tradicionais para barulhar. Como verdadeiros luthiers, elas investigam e experimentam as possibilidades sonoras a que têm acesso no contexto escolar. Assim, sem pedir licença, manipulam uma variedade de paisagens e fontes sonoras, distraindo-se nessa investida ao descobrir que o pátio na hora do lanche e os corredores da escola na hora do brinquedo livre guardam um silêncio aterrorizante; que as canecas do refeitório podem soar de diferentes

\footnotetext{
${ }^{2}$ Acronon é uma música composta por Koellreuter em uma esfera translúcida e transparente como o mundo, feita no ar e não em uma partitura (KOELLREUTER, 2000).
} 
maneiras; que a corrida do lápis sobre a folha de papel é menos intensa que seu percutir na mesa de fórmica da sala de aula; que gritar com a mão na frente da boca produz menos vibração que com ela totalmente aberta; que depois de chover, o balanço faz um barulho menos ruidoso etc. Aqui, as crianças participam da música num tempo integrado de ser, porque são ao mesmo tempo luthiers, performances e compositores.

Logo, podemos dizer que a infância, "como condição da experiência humana" (AGAMBEN, 2001), barulha num tempo aiônico. O termo grego é resgatado da reflexão de Kohan (2004, p.54), na qual o filósofo, valendo-se das definições para o vocábulo tempo, propõe um deslocamento de seu conceito e lugar na infância. Assim, o tempo contínuo, sucessivo, consecutivo, repetido igualmente - chrónos, ou o tempo medido - kairós, cede lugar ao tempo da criança que brinca, criançando - aión, ou melhor, um tempo como ação lúdica que tem fim em si mesma. Por essa razão, Kohan (2004, p.55) afirma: "no reino infantil que é o tempo não há sucessão nem consecutividade, mas intensidade da duração [grifo nosso]" (KOHAN, 2004, p.55). Foi justamente essa intensidade da duração que vivenciei na creche com as crianças, especialmente nos chamados tempos livres de sua rotina escolar. Mesmo que manifestassem prontidão para barulhar em todo lugar e a qualquer hora, a socialização escolar parecia impor-lhes tempos de barulhar comedidos e intervalares. Incorporados no tempo dinâmico de ser, as crianças adentravam provisoriamente os espaços em que lhes era permitido barulhar, soando descontinuidades na intensidade da duração experimentada.

Segundo Bachelard (1988a, p.31), são os instantes descontínuos que formam a duração, pois “o tempo é contínuo como possibilidade, mas descontínuo como ser”. O autor nos lembra que o descontínuo é o natural, já que a continuidade da duração não se apresenta como um dado imediato, mas como um problema. Ao considerar que só há complexidade na retificação, ou seja, quando, a partir da ação materializada, abandona-se o antigo para construir o novo, podemos dizer que o descontínuo provoca instantes notáveis, conquistas interdependentes dessa retificação constante. Bachelard (1988a, p.17) relata que existe uma heterogeneidade "no próprio interior da duração 
vivida, ativa, criadora." Duração que, com o gesto sensível do corpo provocado pela materialidade do mundo, não se dá por continuidades, mas por descontinuidades que, ao conhecer e utilizar o tempo, necessitam "ativar o ritmo da criação e da destruição, da obra e do repouso [...] [Afinal] só podemos reter algo se o reconquistarmos" (BACHELARD, 1988a, p.17). Assim, o tempo de barulhar experimenta as descontinuidades ressoando um sentido compartilhado que precisa da continuidade para existir como forma ou fôrma, na qual a intensidade da duração é o que potencializa o próprio barulhar.

Sendo assim, o tempo de barulhar não é quieto, surdo ou sensato. Ele aceita o ruído da descontinuidade sonora, escuta o mundo e é sensível à poética do devaneio (BACHELARD, 1988b). Como um tempo de maravilhamento, perturbação, espanto e perplexidade, o tempo de barulhar se sustenta na inquietação e consente enfrentar e reconhecer as consistências e resistências da matéria sonora. Por essa razão, o tempo do brinquedo livre dentro da rotina escolar emerge como o tempo previsível do barulhar das crianças, porque é o tempo no qual "as intimidades do sujeito e do objeto se trocam entre si" (BACHELARD, 1990, p.26). Intimidade conquistada através da materialidade reiterada com o mundo que tem na reciprocidade, na sintonia e no contágio o elo estruturante da experiência sensível. Um tempo que suspende o tempo rotineiro, rompendo subitamente o movimento ritmado das coisas e nos arranca do curso normal do viver. Um tempo em estado de mobilização permanente, no qual a música vibra como som, som que nos rodeia acolhida num corpo - essa "fonte primeira do saber e da significação" (DUARTE Jr, 2001, p.216) — que tem dois ouvidos e o sentimento do mundo ao seu dispor.

Se o barulhar é o resultado físico de um movimento motor de Ser, tanto do corpo elástico no espaço (que é condição de soar) quanto do desejo de tocar um corpo que soa (tocar-se como onda sonora, tocar o outro e no outro, tocar o mundo pela escuta) e poder expressar uma composição de relações, ele é movimento do sensível. Sendo da esfera do sensível, esse movimento incorpora uma disposição elementar num permanente estado de excitabilidade sensorial — a sensibilidade —, porta de entrada das sensações que "compreende uma abertura constante ao mundo e nos liga de 
modo imediato ao acontecer em torno de nós” (OSTROWER, 1986, p.12).

Ao investigar a música das crianças na escola compreendi que parece existir uma ordem social para a música nas culturas da infância. Essa ordem estabelece que, para as crianças, música é barulho e elas barulham no limite do risco: risco físico (de se deparar com a constituição acústica da onda sonora, barulhando), risco da pregnância (de se verem provocadas e envolvidas obrigatoriamente na escuta, reproduzindo interpretativamente, expressando, afirmando ou negando coerências musicais instituídas socialmente), risco da criação (quando, poeticamente, inventam música). Porém, a prática social faz com que as crianças logo compreendam que a música é um jogo sonoro de regras em movimento, uma forma instituída a partir da sensibilidade auditiva, organizando a experiência sensorial e estabelecendo relações que permitem uma extensão de sentidos aurais relacionados às "coerências constituídas" (CRUCES, 2002) nas socializações infantis.

Aqui, para chegar à música legitimamente constituída, a criança não necessita passar pelo barulho. Não é uma questão de causa e efeito. Todas as crianças barulham. Todas as crianças entoam. Todas as crianças se movimentam com sons. Todas elas expressam o inabalável encantamento por viver o som como elemento orgânico, efêmero, irrepetível, dissonante, testando as inevitabilidades físicas da onda sonora. Algumas crianças são mais sonoras, outras mais silentes. Algumas expressam vocalmente com maior ou menor intensidade suas criações, outras nunca apontam essa direção. Todas elas estão no caos ou na organização simultaneamente, sem separações, fazem um e outro, um com o outro, um no outro, sem querer significar e sim marcar sua existência.

Considero que o grande desafio do pesquisador se relaciona à sua capacidade de escutar o barulhar das crianças na heterofonia de seu ressoar. A escolha da música como uma linguagem heterofônica ao invés de polifônica quer sublinhar que a música das crianças se faz com experimentação de diferentes fontes sonoras soando ao mesmo tempo, vozes independentes que, ao produzir dissonância e aleatoriedade, acabam por estabelecer uma outra forma ou fôrma 
contrapontística, sem impor modelos e fórmulas a seguir. Nesse momento, o pesquisador de música que pretenda escutar a infância necessita abandonar as hierarquias legítimas impostas historicamente para, improvisadamente, expor a sua cantoria do Repente, isto é, o seu testemunho de organizar sonoridades como a expressão das diferentes sociedades e das singularidades de ser.

Por escutar sensivelmente a dissonância e aleatoriedade da música nas culturas infantis, fui construindo os referenciais para entender o barulhar das crianças, estando simultaneamente no tempo presente e na abertura de novos possíveis. Na música, o barulhar é a força que habita a criança e que nos esforçamos por entender. Encontro alcançado por aqueles investigadores que se arriscam a enfrentar a processualidade inventiva do universo investigativo.

Logo, pela complexidade do campo e pluralidade envolvida no barulhar infantil, a pesquisa com música na infância acaba por envolver diferentes campos científicos, cruzando maneiras de entender a potência poética das crianças à medida que aceita que elas próprias também nos ensinem as formas de fazer pesquisa. Nessa hora, a paisagem sonora e suas significações na rotina escolar parecem emergir, afetando diretamente os comportamentos e estilos de vida musical das crianças. Se por um lado existe uma pluralidade e complexidade de patrimônios de disposições, stocks e competências incorporadas pelas crianças ao viverem na escola, por outro, parece haver uma variedade de contextos de efetivação, de institucionalização da cultura legítima e de variações intra e inter individuais (LAHIRE, 2006) que aparecem livre, espontânea e improvisadamente entre o barulhar. Tais propósitos emergem na expressão sonora infantil, justapondo, sobrepondo, interpondo e impondo as dissonâncias individuais e as consonâncias coletivas simultaneamente, no exercício cotidiano de simplesmente deixar-se barulhar.

\section{“a paisagem sonora escolar"}

Ao compreender que uma paisagem sonora não se constitui apenas como um lugar físico, mas impõe-se como um território que incorpora modos diversos de soar através de diferentes culturas e indivíduos, é importante destacar que a paisagem sonora escolar é um espaço físico que "respira, escuta e fala" (MUTANDAS, 2007) da escola, das crianças, das adultas-professoras, dos 
funcionários, dos governos estabelecidos, da infância, etc. Nele estão envolvidos, relacionados e criados uma série de sensações, idéias e sentimentos que contínua e dinamicamente emergem na cultura de pares das crianças.

Mesmo que não haja uma intencionalidade pedagógica expressa no projeto acústico de uma escola, uma paisagem sonora ressoa incessantemente eventos sonoros articulados naquele cenário. Logo, sem constituir um derivado acidental, tal paisagem é uma construção feita deliberadamente por seus promotores, demarcando um jeito de ser e pensar as sonoridades que acabam por instituir um projeto acústico escolar.

Um projeto acústico é, pois,

um modelo de paisagem sonora que pergunta de que modo a orquestração e a forma das sonoridades do ambiente podem ser aperfeiçoadas para produzir riqueza e diversidade de efeitos que não sejam, todavia, destrutivos para a saúde ou o bem-estar humano (SCHAFER, 2001, p.366).

Assim, pela contemplação, pela interferência e/ou pela absorção, evidenciam-se escutas comprometidas com determinados espaços. De modo geral, os projetos acústicos podem ser concebidos por músicos ou cientistas sociais que procurem descobrir os princípios da qualidade estética do ambiente, tanto no que diz respeito à preservação e avaliação dos sons como de sua proposição imaginativa quando os músicos criam ambientes acústicos. Na constituição de um projeto acústico estão envolvidos diferentes princípios de julgamento e aperfeiçoamento das paisagens sonoras que o planejador mostra à sociedade para que ela decida o que pretende escutar.

Portanto, a paisagem sonora de uma escola é o resultado do projeto acústico empreendido por seus realizadores, cenário sonoro institucionalizado da ação infantil. Lugar dotado de dinâmica em constante trânsito porque, nesse espaço sônico, os sentidos podem mudar constantemente em função dos usos e investimentos ali empreendidos, além de absorver as dinâmicas e os processos que mobilizam esses lugares. Então, toda a relação com uma paisagem sonora é também uma tentativa de audição e captura dos possíveis sentidos desse lugar. Isso porque o sentido sônico de um lugar nunca é dado, ele depende de tradução e vivência social e cultural de seus participantes 
(SCHAFER, 2001).

Dessa forma, experimentei no campo (LINO, 2008) uma diversidade de impressões e expressões que demonstravam a competência sonológica (SCHAFER, 2001) das crianças. Nesse momento entendi que, para as crianças, a paisagem sonora escolar emergia como mote provocador da expressão musical. Segundo Schafer (2001, p.170), “a impressão atrai e coordena; a expressão afasta e projeta". O compositor entende que, sendo apenas metade da percepção, a impressão concilia a informação que recebemos do ambiente. No entanto, juntas, impressão e expressão nos potencializam, pela inteligência, a competência sonológica. Tal competência, longe de ser mera recepção de informação sensorial, é o conhecimento do próprio fazer, ou melhor, o conhecimento das propriedades sonoras e a capacidade de projetá-las (SCHAFER, 2001, p.216-217). Dessa forma, a competência sonológica é alcançada pelo conhecimento implícito que nos permite a compreensão das formações sonoras (SCHAFER, 2001, p.363).

Neste contexto, quando entendemos que as mesmas sonoridades podem ter diferentes funções e significados através de diferentes culturas é porque concebemos que existe uma socialização à impressão e expressão sônica experimentada nos múltiplos contextos de nossas sociedades. Se "o ouvido, este órgão do medo, só alcançou tamanha grandeza na noite escura e na penumbra de cavernas obscuras e florestas, bem de acordo com o modo de viver da era do receio" (NIETZSCHE, apud CAESAR, 2001, p. 5), esse ouvido tinha um modo de tocar o mundo que, longe de ser um ato passivo de incorporação da paisagem sonora, implicava a habilidade de interpretar informações sobre sua tranquilidade ou perigo. Nesse contexto, a habilidade auditiva impunha-se como uma necessidade vital àquela sociedade.

As crianças por mim investigadas (LINO, 2008) conheciam pela escuta quem se aproximava no corredor central, quem estava falando no banheiro, que atitude deveriam ter em determinada paisagem sonora do cotidiano escolar. Sabiam que no recreio podiam barulhar à vontade, enquanto na sala da enfermagem o silêncio se impunha como forma de acolhida e atenção. Elas tinham a escuta como interface crucial para compartilhar informações do mundo constituídas socialmente. 
Isso porque "o sistema auditivo pode processar a entrada de energia acústica e criar sistemas neurais, mas escutar envolve altos níveis cognitivos que extraem informações e interpretam significados vivenciados socialmente” (TRUAX, 1992, p.376 apud SCHAFER, 2001, p.354).

Portanto, para essas crianças, a paisagem sonora escolar se constituía em mais um tempoespaço de brincar e, sempre que lhes eram oportunizados momentos de liberdade (fora da monitoração dos adultos), penetravam o interior dessas paisagens sonoras para explorar sonoridades, experimentar qualidades acústicas, escutar silêncios, deixar-se inundar pela vibração da onda sonora, propor outras formas de soar. Dessa forma, o linguajar ${ }^{3}$ tão típico das culturas infantis tinha na paisagem sonora escolar um território de expansão, experimentação e interação constante, conferindo significados simbólicos que se criavam e recriavam dinamicamente para além da especificidade aural. Ao linguajar através dos diferentes recantos dispostos na grande paisagem escolar, as crianças promoviam deslocamentos sonoros com os pares, com os adultos e com as transformações envolvidas natural ou artificialmente no próprio ambiente, mobilizando sentidos que congregavam intimidade, empatia e diversão na incidência corporal de expressar simultaneamente o real e o ficcional.

Ao longo de toda a investigação percebi uma necessidade constante e sempre dissimulada das crianças de atravessar paisagens sonoras. Individualmente, em duplas ou em pequenos grupos, pareciam brincar livremente (divertindo-se muito) à medida que abandonavam a paisagem sonora em que deveriam estar, pela organização da rotina escolar, para irromper em outro espaço sônico institucionalmente disposto no cotidiano escolar. Conforme fui perseguindo o adentrar das crianças pelas diversas paisagens sonoras da escola, descrevendo-as nos diários de campo e nos retratos sonoros construídos, fui percebendo como elas, muitas vezes, apenas queriam experimentar sonoridades para escutar relações sonoras instituídas ou expor singularidades polivalentes. Também

\footnotetext{
${ }^{3}$ Merleau-Ponty, em texto de 1951, publicado na obra Signos (1991), foi o primeiro autor a referir-se à atividade "linguageira" da linguagem, a qual "realiza a mediação entre a minha intenção ainda muda e as palavras, de tal modo que minhas palavras me surpreendem a mim mesmo e me ensinam o pensamento" (MERLEAU-PONTY, 1991, p. 94).
} 
constatei que todo o seu sonorizar na escola se relacionava ao tempo e lugar constituídos social e culturalmente para ser criança naquela instituição.

Nesse momento, compreendi como lhes encantava quebrar os silêncios estacionários existentes no corredor da creche ou na sua sala de aula vazia e escura (quando toda a turma já estava no pátio brincando) e reviver memórias sonoras perdidas. No primeiro caso, as paisagens sonoras funcionavam como recipientes de silêncio, podendo ser quebradas a qualquer momento a partir da mobilização de sua própria escuta, da escuta do outro, ou de uma provocação sonora externa (por exemplo, a passagem de um avião no pátio da creche). Isso porque a paisagem sonora escolar não existia apenas para ser compreendida e identificada sonoramente pelas crianças, mas para deixar irromper ali o seu jardim sonoro: "qualquer lugar de prazeres acústicos. Pode ser uma paisagem sonora natural ou um lugar submetido aos princípios do Projeto Acústico. O jardim sonoro pode incluir também um Templo de Silêncio, um templo de escutas" (SCHAFER, 2001, p.365). Um tempo-espaço descontínuo que serve apenas à diversão e afetividade.

No segundo caso, as crianças pareciam querer reviver espaços acústicos que relembrassem seu tempo de pertencimento ao contexto escolar:

Isadora acaba de almoçar e está sentada no colchão na sala do soninho, deve dormir. Mesmo que todas as professoras ali presentes salientem essa necessidade, a menina olha para sua professora e diz: quando eu estudava contigo lá (refere-se à sala ocupada pelos bebês da creche) tu cantava prá nóis durmi.....pur quê tu não canta mais aquelas músicas prá durmi qui eu era pequena? (Diário de campo, 24/10/06).

O canto solicitado por Isadora reivindica um momento específico conhecido pela criança em sua socialização na creche. Frequentadora da instituição desde bebê, Isadora sabe que, no berçário, a atual adulta-professora the entoava acalantos na hora do soninho, acompanhados de um embalar aconchegante que convidava ao relaxamento. Atualmente, no Maternal II, a menina não é embalada na hora do soninho pela voz da adulta-professora. Isadora interroga essa mudança de atitude. Mesmo que na escola, para as crianças maiores, a voz não penetre mais o ouvido antes da hora do soninho, nem o toque enlace e conduza ao embalo do sono, as crianças têm na memória essa experiência. 
Logo, a paisagem sonora escolar como um cenário institucionalizado para a ação infantil constituiu-se na multidimensionalidade acústica articulada pelas crianças, pelas adultas-professoras e pela instituição naquele espaço sônico de pertencimentos sentidos, explorados e vividos que fazem os sons vibrarem atrelados às significações e às atribuições simbólicas apreendidas social e culturalmente. As crianças têm competência sonora para conhecer e modificar as marcas sonoras definidas institucionalmente e o fazem insistentemente, produzindo outras sonoridades, outras paisagens sonoras e instaurando outros sentidos acústicos. No entanto, nem sempre são contempladas em seu escutar. Isso porque o movimentar das materialidades sonoras de uma paisagem escolar não opera apenas com sons, mas com a escuta, isto é, “com a atividade que o ouvido desenvolve em torno do que ouve" (CRUCES, 2002, p.4).

Estar socializado como aluno da creche significa também perceber auditivamente os sons que emolduram aquela paisagem sonora, isto é: escutar os diferentes cantos dos pássaros que habitam as árvores dos pátios através das diferentes estações do ano; reconhecer que o som mais intenso do tráfego dos carros na avenida sinaliza a chegada da hora do soninho ou da saída; entender que o som friccionado conquistado pelo atrito dos pés calçados com areia dentro da caixa de brinquedos feita de madeira produz uma sonoridade que "arrepia” (Diário de campo, 26/01/07); que o gira-gira, esporadicamente, pode se transformar num "monstro" pelo forte ruído produzido pela falta de óleo em sua engrenagem (Diário de campo, 04/10/06); que os passos percorridos até o topo do escorregador grande ou pequeno preparam um silêncio espirado, contemplado como expectativa; que os balanços convidam a vocalizes e papos ao vento; que "o coração não pára" (Isadora, Diário de campo, 24/11/06) quando se sobe no trepa-trepa; que correr sozinho pelo corredor vazio faz a voz querer gritar; que a sala de Educação Física "dá um grito mais forte" (Gabriel, Diário de campo, 21/11/06) porque tem eco; entre tantos outros aspectos acústicos que poderia enumerar.

As pequenas significações aurais destacadas acima representam o quanto as crianças são sensíveis às paisagens sonoras do contexto escolar, mobilizando-se pelo espaço e tempo 
institucionalizado a partir das referências simbólicas que têm na audição sua morada. Assim, a organização da paisagem sonora escolar como um cenário institucionalizado da ação infantil comunica um projeto acústico que parece contemplar "o silêncio como regra do movimento" (LAOTZU, 1962; apud SCHAFER, 2001, p.330). Nesse sentido, a disposição da mobília e dos espaços através das diferentes paisagens sonoras estabelecidas no contexto escolar ecoa um modelo de espaço sônico para a Educação Infantil que pode vir determinando modos lineares e determinados de soar, desconsiderando que, para as crianças, "todo o silêncio esta grávidos de sons" (CAGE, 1976). E elas não se cansam de encontrar, experimentar e explorar essas sonoridades.

Neste contexto, as crianças desafiavam a pregnância de certezas e receitas sonoras a seguir na direção do poético. Isso significa dizer que, ao se deixarem brincar com as materialidades da paisagem sonora escolar, as crianças acabavam por movimentar o silêncio imposto ou exposto dessa paisagem, fazendo emergir sua singularidade plural. Tal atividade não recusa o determinado e o medido, o ruído, o silêncio ou a canção, mas só acontece na imprevisibilidade de encontros sentidos para soar. Encontros que, como as cantorias do trovador repentista, têm no improviso a forma da ação lúdica para ouvir a sua própria voz cantando.

\section{MUSIC, RESEARCH AND CHILDHOOD: SONGS OF REPENTE}

\section{Abstract}

This paper considers the research on music with children, pointing out the emergent need of the researcher's inventive processuality. It presents two listening points considered in the author's research when she intentionally intended to develop improvised ways of building the research by listening to the music of children in school. Considering the field of Children Sociology, noising is highlighted here as children's music whereas the sounding landscape is indicated as the 
institutionalized scenario of children's actions, revealing two listening points to develop the reflection about the research process in music with children and in childhood.

Key words: Research in music with children; children cultures and music; school sounding landscape.

\section{Referências}

ABRAMOWICZ, Anete. Conferência realizada no II Seminário de Pesquisa sobre crianças e infâncias: Perspectivas Metodológicas. 08 a 10 de setembro 2010. Universidade do Estado do Rio de Janeiro (UERJ)

AGAMBEN, G.. Infância e história. Buenos Aires: Adriana Hidalgo, 2001.

BACHELARD, Gaston. A dialética da duração. São Paulo: Ática, 1988a.

BACHELARD, Gaston. A poética do devaneio. São Paulo: Martins Fontes, 1988b.

BACHELARD, Gaston. A terra e os devaneios do repouso. São Paulo: Martins Fontes, 1990.

BARBOSA, Maria Carmen Silveira. Rotinas na Educação Infantil. Porto Alegre: Artmed, 2006.

BARBIER, René. A escuta sensível em educação. Cadernos da ANPED, Porto Alegre, n.5, p.182196, 1993.

BARBIER, René. A pesquisa-ação. Brasília: Líber Livro, 2002.

BRITO, Teca Alencar de. Por uma educação musical do pensamento: novas estratégias de comunicação. São Paulo: Departamento de Comunicação e Semiótica, Pontifícia Universidade Católica. Tese de Doutorado. 2007.

CAESAR, Rodolfo. A escuta como objeto de pesquisa. Revista da ANNPPOM. Opus, n. 7, fevereiro, 2001. <www.anppom.com.br/opus7/dudatext.htm>. Acesso em 24/04/2006

CAGE, John. Silence. Middletown: Wesleyan University Press, 1976.

CAMPBELL, Patricia S. Songs in their heads. New York: Oxford University Press, 1998.

CRUCES, Francisco. Niveles de coherencia musical: La aportación de la música a la construcción de mundos. Revista Transcultural de Música - Transcultural Music Review. São Paulo, 2002. Disponível em: <http://www.sibetrans.com/trans/index.htm>. Acesso em: 07 jul.2007. 
DUARTE JUNIOR, João Francisco. O sentido dos sentidos. Curitiba: Criar Edições, 2001.

DUBET, François. Le d'eclin de l'institution. Paris: Seuil, 2002.

FOUCAULT, M. Vigiar e punir. Petrópolis: Vozes, 1997.

GIDDENS, A. Transformações da intimidade: sexualidade, amor e erotismo nas sociedades modernas. Oieras:Celta Editora, 1995.

GORDON, L. Paul Willis: educação, produção cultural e reprodução social. Teoria e Educação, n.1, p.134-47, 1990.

GREEN, Lucy. Music, gender, education. Cambridge: Cambridge University Press, 1997.

HORTÉLIO, Lydia. Teatro brincarte. Rio de Janeiro: FUNARTE, 1977.

HOYUELOS, Alfredo. La estética en el pensamiento y obra pedagógica de Loris Malaguzzi. Ediciones Octaedro: Barcelona, 2006.

JAMES, Allison; JENKS, Chris; PROUT, Alan. Theorizing childhood. Cambridge: Polity Press, 1998.

KOHAN, Walter O. (Org.) Lugares da infância: filosofia. Rio de Janeiro: DP\&A, 2004.

KUHLMANN Jr, Moysés. Infância e educação infantil: uma abordagem histórica. Porto Alegre: Mediação, 1998.

LAROSSA, Jorge B. La experiencia de Ia lectura: estudios sobre literatura y formacion. Editorial Laertes, 1996.

LAHIRE, Bernard. L'homme pluriell. Lisboa: Instituto Piaget, 2001.

LAHIRE, Bernard. A cultura dos indivíduos. Porto Alegre: Artes Médicas, 2006.

LINO, Dulcimarta Lemos. Barulhar: a escuta sensível da música nas culturas da infância. Faculdade de Educação, Universidade Federal do Rio Grande do Sul, Porto Alegre, 2008. Tese de Doutoramento.

MAFRA, Leila de Alvarenga. A sociologia dos estabelecimentos escolares: passado e presente de um campo de pesquisa em re-construção. In: ZAGO, Nadir; CARVALHO, Marília; VILELA, Rita (Orgs.) Itinerários de pesquisa: perspectivas qualitativas em Sociologia da Educação. Rio de Janeiro: DP\&A, 2003. p.109-136.

MALAGUZZI, L. L'ombra e il pallottoliere dei bambini. In: Tuttto ha um'ombra meno le formiche. Reggio Emilia: Comune di Reggio Emília, 1990. p.24-32.

MERLEAU-PONTY, Maurice. Signos. São Paulo: Perspectiva, 1991.

MUNTADAS, Antoni. Palestra. In: EVENTO COPESUL/BRASTEMP, 19 nov 2007. Porto Alegre. Anais eletrônicos... Porto Alegre. Fronteiras do Pensamento. Disponível em: <www. fronteirasdopensamento.com.br>

NABUCO, Fundação João. Poetas do Repente. Recife: Fundação João Nabuco, 2008. 
OSTROWER , Fayga. Criatividade e processos de criação. Petrópolis: Vozes, 1986.

PINTO, Manuel. A infância como construção social. In: PINTO, M.; SARMENTO, M. (Orgs.) As crianças contextos e identidades. Minho: CE1,1997a. p.33-73.

RICHTER, Sandra Regina Simonis. A dimensão ficcional da arte na educação da infância. 2005. 280f. Tese (Doutorado em Educação) -Faculdade de Educação, Universidade Federal do Rio Grande do Sul, Porto Alegre, 2005.

SARMENTO, Manuel Jacinto; PINTO, Manuel; VASCONCELLOS, Vera (Orgs). Infância (in) visível. Araraquara: Junqueira \& Marin, 2007.

SCHAFER, Murray. A afinação do mundo: uma exploração pioneira pela história passada e pelo atual estado do mais negligenciado aspecto do nosso ambiente: a paisagem sonora. São Paulo: UNESP, 2001.

SCRATON, Phil (Ed). Childhood in crisis? Londres: UCL Press, 1997.

SIROTA, Régine. L'émergence d'une sociologie de l'enfance: évolution de l'object, évolution du regart. Éducation et sociétés. Revue Internationale de Sociologie de l'Education, Sociologie de L'enfance, Paris, n.1, p.9-34, Paris 1998.

TAYLOR, Frederik. Princípios de administração científica. São Paulo: Atlas, 1966.

VILLA, F. G. Teoria sociológica de la educacion. Salamanca: Amarú, 1997.

ZAGO, Nadir; CARVALHO, Marília Pinto de; VILELA, Rita Amélia Teixeira (Orgs.) Itinerários de pesquisa: perspectivas qualitativas em sociologia da educação. Rio de Janeiro: DP\&A, 2003.

WISNIK, José Miguel. Sem receita: ensaios e canções. São Paulo: Publifolha, 2004.

WOODWARD, Kathryn. Identity and difference. Open University: SAGE, 1997.

WYNESS, M; HARRISON, L; BUCHANAN, I. Childhood, politics and ambiguity: towards an agenda for chilfren's political inclusion. Sociology, v.38, n.1, p.81-99, 2004.

Data de recebimento: $10 / 09 / 2010$

Data de aceite: 18/09/2010 